Title:

Author(s):

Submitted to:

\section{Los Alamos}

NATIONAL LABORATORY
Waste Minimization in Chrome Plating

Jay Scheuer, P-24

Kevin Walter, MST-4

Michael Nastasi, MST-4
DOE Office of Scientific and Technical Information (OSTI)
DISTRIBUTION OF THIS DOCUMENT IS UMMTTED
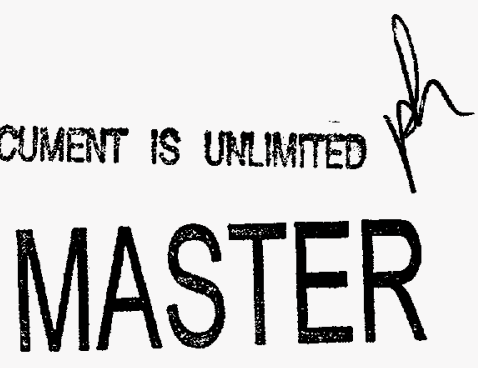

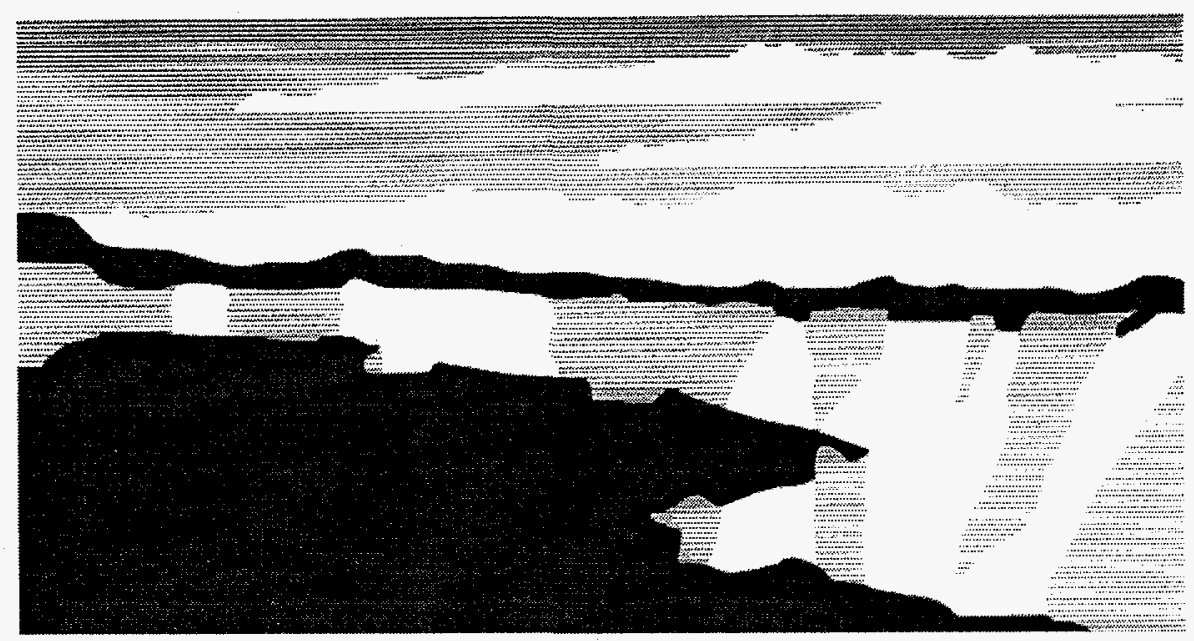

Los Alamos National Laboratory, an affirmative action/equal opportunity employer, is operated by the University of California for the U.S. Department of Energy under contract W-7405-ENG-36. By acceptance of this article, the publisher recognizes that the U.S. Government retains a nonexclusive, royaltyfree license to publish or reproduce the published form of this contribution, or to allow others to do so, for U.S. Government purposes. The Los Alamos National Laboratory requests that the publisher identify this article as work performed under the auspices of the U.S. Department of Energy. 


\section{DISCLAIMER}

Portions of this document may be illegible in electronic image products. Images are produced from the best available original document. 


\section{DISCLAMMER}

This report was prepared as an account of work sponsored by an agency of the United States Government. Neither the United States Government nor any agency thereof, nor any of their employees, makes any warranty, express or implied, or assumes any legal liability or responsibility for the accuracy, completeness, or usefulness of any information, apparatus, product, or process disclosed, or represents that its use would not infringe privately owned rights. Reference berein to any specific commercial product, process, or service by trade name, trademark, manufacturer, or otherwise does not necessarily constitute or imply its endorsement, recommendation, or favoring by the United States Government or any agency thereof. The views and opinions of authors expressed herein do not necessarily state or reflect those of the United States Government or any agency thereof. 


\title{
Waste Minimization in Chrome Plating
}

\author{
Jay Scheuer*, Kevin Walter, and Michael Nastasi
}

\begin{abstract}
This is the final report of a one-year, Laboratory-Directed Research and Development (LDRD) project at the Los Alamos National Laboratory (LANL). Traditional wet chemical electroplating techniques utilize toxic materials and pose environmental hazards in the disposal of primary baths and waste waters. Pollutants include metals and nonmetals, such as oil, grease, phosphates, and toxic and organic compounds. This project is focused on development of plasma source ion implantation (PSII), a novel and cost-effective surface modification technique, to minimize and ultimately eliminate waste generated in chrome plating. We are collaborating with an industrial partner to design material systems, utilize the PSII processes in existing Los Alamos experimental facilities, and analyze both material and performance characteristics.
\end{abstract}

\section{Background and Research Objectives}

Steel machine tooling and processing equipment are found everywhere in government and commercial manufacturing. Protective coatings are routinely applied to improve tooling performance, e.g., to reduce wear and friction and enhance corrosion resistance. However, coatings often are applied by traditional wet chemical electroplating techniques that utilize toxic materials and pose environmental hazards in the disposal of primary baths and waste waters. Pollutants include metals and nonmetals, such as oil, grease, phosphates, and toxic and organic compounds. The goal of this project is to reduce the chrome plating waste stream by developing advanced, plasma-based, materials processing technologies as environmentallyconscious and cost-effective enhancements and alternatives to traditional chrome plating.

\footnotetext{
*Principal investigator, e-mail: jts@lanl.gov
} 
Ion surface modification is a proven technology for the formation of low-friction, highstrength, corrosion-resistant surfaces. Treated parts possess more durable surfaces that are well integrated with the base material. Implantation is not a coating, but rather a transformation of an already existing surface layer. Many interface issues that are critical for coatings technologies, e.g., adhesion and delamination, are irrelevant with implantation.

Despite the promise of ion beam processing, traditional, line-of-sight beamline technology is considered too expensive and complicated for most surface modification applications.

Plasma source ion implantation (PSII) and plasma immersion ion processing (PIIP) are economical technologies to satisfy industry needs. PSII is a non-line-of-sight ion-implantation technique that reduces the complexity and cost of traditional beam implantation. PIP is a logical extension of PSII, which combines ion bombardment with plasma deposition allowing deposition of adherent coatings more than 10 microns thick.

The two stages of this project are 1) use PSII to extend the life of chrome plating and 2) use PIIP as a complete alternative to chrome plating. To accomplish these tasks, a flexible implantation and deposition tool will be made operational in the Center for Materials Science at Los Alamos to augment the capability of the existing PSII facility (the largest in the world). This new PIIP tool will allow exploration of the parameter space resulting in the development of replacements to chrome plating, without hindering processing of industrial components in the large facility.

LANL materials and plasma scientists have processed manufacturing tooling in our existing experimental facilities and analyzed both material and performance characteristics. Interested industrial partners have been identified through Empire Hard Chrome, a major chrome plater with a key market position and a customer base of over 60 US manufacturers.

\section{Importance to LANL's Science and Technology Base and National R\&D Needs}

Our project addresses a major strategic direction of the LANL Environmental Management Program: industrial waste reduction and pollution prevention. We offer a technical solution to an acknowledged environmental problem in the approach outlined below. The potential market of US manufacturers that may benefit from this technology is enormous. The major LANL core competencies addressed by this work are: nuclear and advanced materials and nuclear science, plasmas, and beams. In addition, this project supports the following Laboratory technical goals: "great science" by providing a science base for plasma and beam processing in materials technology and "industry" by establishing industrial partnerships. 


\section{Scientific Approach and Results to Date}

Los Alamos researchers have developed and demonstrated, on an industrially-relevant scale, the PSII surface modification technique that will improve production efficiency and quality. This technology could revolutionize manufacturing, allowing the use of highperformance machinery with reduction (or elimination) of hazardous wet chemical processes that eventually may be banned by the Environmental Protection Agency. PSII processing costs are projected to be 5 to 10 times lower than conventional line-of-sight implantation and comparable to presently-accepted surface modification techniques.

We have used LANL's PSII facility, the largest ion implanter in the world, to improve surface properties of steel manufacturing equipment. LANL material scientists have defined material systems and performed characterization and wear tests of implanted parts.

A crucial addition to the PSII capability is an experimental PIIP device (1.3-m-diameter by $1.8-\mathrm{m}$-long), which is being developed for materials processing with metal-organic precursors. The use of high vapor pressure metal-organic precursors will facilitate scale-up and enable the PIIP process to easily combine ion implantation and energetic ion deposition, offering the ultimate flexibility in surface modification processing. Once PIIP processes are fully developed in the experimental plasma device, the processing technology will be transferred to the larger, PSII facility for full industrial application.

Our technical work to date has focused on PSII of chrome-plated test coupons. These test coupons were chrome plated at Empire Hard Chrome and characterized before and after processing using Rutherford backscattering analysis to determine implanted dose, nanoindentation to determine near surface hardness, and pin-on-disk wear testing to determine wear resistance.

In one study, ammonia, rather than the traditional $\mathrm{N}_{2}$, was used as the nitrogen source for PSII to increase the depth of penetration for a given implant voltage. Laboratory pin-ondisk testing showed a 4-fold increase in $\mathrm{Cr}$ lifetime, and nanohardness measurements indicated a 25\% increase in hardness [1]. A comparative PSII study using ammonia, methane, and oxygen is reported in Ref. [2]. All three gases were found to increase the surface hardness and wear resistance through the formation of hard compounds, namely polycrystalline chromiumnitride $(\mathrm{CrN})$, chromium-carbide $\left(\mathrm{Cr}_{3} \mathrm{C}_{2}\right)$, and chromium-oxide $\left(\mathrm{Cr}_{2} \mathrm{O}_{3}\right)$.

Several industrial partners have been identified with the help of Empire Hard Chrome. Promising results for PSII-processed industrial laboratory samples for International Paper (IP) and Alcoa motivated the implantation of a $3 \times 8$ - $\mathrm{ft}$ press plate for IP and a 16-in diameter $\mathrm{x} 1$ - $\mathrm{ft}$ long mill roll for Alcoa. The IP press plate, now being tested in production, is the world's largest ion implanted surface. Implantation of the inner diameter of a locomotive cylinder was 
performed for GM Electromotive. Chrome plated cotton picker spindles implanted for JI Case will be evaluated in a comparative study under actual "field" conditions. Major components for the PIIP system have been identified and are being assembled in the Center for Materials Science with initial operation expected in late FY95.

As a result of the above described work, Empire Hard Chrome is taking delivery of the world's first commercial PSII unit in 1995.

\section{References}

1. Scheuer, J., K.Walter, J. Blanchard, D. Rej, and M. Nastasi, "Plasma Source Ion Implantation of Ammonia into Electroplated Chromium," in Advances in Coatings Technologies for Corrosion and Wear Resistant Coatings, edited by A.R. Srivatsa, C.R. Clayton, and J.K. Hirvonen, pp 119-126, The Minerals, Metals and Materials Society, (1995).

2. Walter, K., J. Scheuer, P. C. McIntyre, P. Kodali, Ning Yu, and M. Nastasi, "Increased Wear Resistance of Electrodeposited Chromium through Applications of Plasma Source Ion Implantation Techniques," submitted to Surface Coatings Technology (1995). 